\title{
Comparando la informatividad textual desde el paradigma traductológico del funcionalismo
}

\author{
Ana María García Álvarez \\ Universidad de las Palmas de Gran Canaria \\ agarcia@dfm.ulpgc.es
}

Recibido: 25 de junio de 2010

Aceptado: 20 de noviembre de 2010

\section{RESUMEN}

El modelo funcional de Hulst (1995) constituye uno de los instrumentos más eficaces para analizar los productos de traducción en relación con sus textos originales. Dicho modelo no solo toma en cuenta enfoques pragmáticos y modelos traslativos orientados hacia el análisis textual (entre otros, Nord, 1991; Reiss, 1971; House, 1977) sino también aspectos teóricos procedentes de la lingüística del texto, el análisis del discurso y otras teorías funcionalistas basadas en la lengua en uso. Una de sus contribuciones metodológicas consiste en analizar y comparar la informatividad (Beaugrande \& Dressler, 1981) entre textos. En el presente artículo se describirá el modelo en relación con la informatividad y se aplicará a un caso de estudio para demostrar su eficacia.

Palabras clave: traducción y funcionalismo, análisis textual y traducción, informatividad, pragmática.

Comparing textual informativity through functionalism in translation

\begin{abstract}
The functional model of Hulst (1995) is one of the best instruments to analyse translation products in relation with their originals. It takes into account not only pragmatic approaches and models for translation oriented text analysis (Nord, 1991; Reiss, 1971; House, 1977 among others) but also theories in the field of texts linguistics, discourse studies and other functional theories on language use. One of its methodological contributions is to analyse informativity (cf. Beaugrande \& Dressler, 1981) between texts. In this presentation, the model will be described and applied in relation with informativity by means of an example analysis to show its effectiveness.
\end{abstract}

Keywords: translation and functionalism, text analysis and translation, informativity, pragmatics . 
Sumario: 1. El modelo funcional de Hulst. 1.1. Las relaciones de contenido. 1.2. Las relaciones de apoyo por interacción. 2. Aplicación del modelo: analizando la informatividad de un texto. 3. Comparando la informatividad entre textos: un caso de estudio. 4. Conclusiones.

\section{El modelo funcional de Hulst}

El modelo funcional de análisis textual de Hulst (1995), cuyo objetivo metodológico es comparar los diferentes niveles textuales que conforman los textos metas y sus respectivos textos originales desde el paradigma del funcionalismo, constituye uno de los instrumentos más completos de comparación de los productos textuales. Dicho modelo no solo recoge los enfoques pragmáticos aplicados a la traducción de Reiss (1971), Nord (1991), House (1977) y otros traductólogos, sino que también contempla teorías de la lingüística textual, de análisis del discurso y otras teorías sobre el texto en uso. Una de sus contribuciones metodológicas consiste en analizar el nivel textual relacionado con la macroestructura y la informatividad (Beaugrande\&Dressler, 1981). En este sentido, la conectividad macroestructural es el producto de las relaciones funcionales de información específica entre las proposiciones o actos locutivos en el nivel microestructural, es decir, las relaciones de coherencia, también denominadas por Mann y Thompson (1988) como "relaciones retóricas". Por cuestiones de espacio nos limitaremos a describir las relaciones funcionales de información entre proposiciones, principalmente en el nivel microestructural, estadio textual que denominamos por otro lado "informatividad", en alusión a uno de los criterios de textualidad establecidos por Beaugrande y Dressler (1981).

Dentro de estas relaciones de coherencia entre los actos locutivos, Hulst (1995:111) establece una distinción entre las relaciones que conllevan un marcado contenido informativo y las relaciones cuya función es señalar al lector el camino en el texto. El primer grupo se denomina relaciones de contenido; el segundo grupo comprende las relaciones de apoyo por interacción.

Paralelamente a estas dos clasificaciones, cabe señalar un dato importante establecido por Hulst que atañe a las relaciones entre los actos locutivos desde su aspecto comunicativo-funcional: existen relaciones tanto jerárquicas (un acto locutivo se subordina a otro acto locutivo) como no jerárquicas (una serie de actos locutivos funcionan con el mismo estatus o peso comunicativo). Dentro del grupo de las relaciones de contenido nos encontramos con ambas manifestaciones, es decir, tanto las relaciones jerárquicas como no jerárquicas. En el caso de las relaciones de apoyo por interacción, las relaciones entre actos locutivos suelen ser jerárquicas, donde una serie de actos locutivos quedan subordinados a otro acto locutivo.

\subsection{Las relaciones de contenido}

Las relaciones de contenido comprenden cuatro tipos básicos establecidos por Hulst. En primer lugar cabe destacar las relaciones descriptivas, las cuales repre- 
sentan la necesidad de dar más información sobre el acto locutivo anterior. El lector entiende la primera proposicion, pero necesita saber más acerca de la circunstancia expresada en esta primera proposición. Las relaciones descriptivas aparecen en fragmentos textuales donde se proporciona información sobre determinadas propiedades $\mathrm{y}$ aspectos de objetos, circunstancias o acontecimientos. Estas relaciones no suelen ser jerárquicas, dado que ambos actos locutivos son igualmente importantes respecto de su función comunicativa en el texto, si bien esto no quiere decir que una relación jerárquica sea imposible. Este tipo de relación suele aparecer en determinados enunciados de textos enciclopédicos, en fragmentos descriptivos del artículo periodístico y del artículo de divulgación científica, o en aquellos textos literarios donde se emplea el recurso textual de la narración.

Las relaciones descriptivas se dividen a su vez en relaciones de causa (señalan el motivo o la consecuencia de una circunstancia o acontecimiento) y en relaciones por características (señalan todo tipo de características de un objeto, circunstancia o acontecimiento). Las relaciones de causa señalan no sólo el motivo-consecuencia/consecuencia-motivo de un objeto, circunstancia o acontecimiento, sino también factores relacionados, entre otros, con la condición-meta, la actividad-resultado, la presentación-repercusión, la situación-condición o el problema-solución y viceversa. Las relaciones por características proveen información sobre las propiedades de un objeto o concepto, señalando su relación con otros objetos, objeto-contenido u objeto-partes. También indican aspectos relacionados con el tiempo y el espacio (objeto/situación-tiempo; objeto/situación-lugar), y la clase-parte.

Las relaciones aclarativas comprenden el segundo tipo de relaciones de contenido y suelen establecer una relación de tipo jerárquico con otros actos locutivos, ya que desempeñan un papel comunicativo subordinado. Su finalidad en el texto consiste en facilitar la comprensión de determinados actos locutivos. La diferencia entre las relaciones aclarativas y las relaciones descriptivas consiste en que estas últimas proporcionan más información al texto, mientras que aquellas se basan en proporcionar el entendimiento de posibles problemas conceptuales. Suelen aparecer como recurso aclarativo de ciertos tecnicismos (p. ej. en los textos especializados), conceptos o proposiciones. Dentro de este tipo de relaciones entrarían la paráfrasis (como recurso aclarativo normalmente de una abreviatura, un concepto especializado, un referente cultural o proposición especializada), la relación por analogía (la comparación de una circunstancia, objeto o acontecimiento en el texto con otros fenómenos de otros ámbitos), la relación por ilustración (que suele acompañar a la relación descriptiva clase-parte) y una adición aclarativa con respecto a un concepto impreciso en el texto, y que nosotros denominamos en español aposición. Esta adición aclarativa puede estar compuesta por una sucesión de proposiciones con el mismo estatus comunicativo-funcional de aclarar el concepto o proposición precedente.

Otra manera de contribuir a la comprensión textual es por medio de las relaciones de razonamiento, el tercer grupo de relaciones de contenido. En este tipo de relaciones no se trata de aclarar problemas de formulación en el texto de manera retórica, sino de aseverar o afirmar la circunstancia que se está expresando. La relación explicativa, por ejemplo, suele acompañar a las relaciones causales de motivo-con- 
secuencia como refuerzo confirmativo de un determinado criterio o circunstancia expresado en el texto. Este tipo de relación es típica de los textos didácticos o de los artículos de divulgación científica.

Mientras la relación explicativa contribuye a ampliar informativamente un determinado concepto, la relación argumentativa aporta credibilidad al contenido de un acto locutivo, y suele manifestarse en textos persuasivos, comentarios o reseñas. Una relación argumentativa puede resaltar aspectos de una situación expresada en un texto del siguiente modo: argumentos que indican la conveniencia de una situación, argumentos que subrayan la probabilidad de una situación y argumentos que evalúan la calidad de un objeto o situación. Los argumentos en torno a la conveniencia de una situación pueden adoptar una postura objetiva por parte del autor del texto en el sentido de que toma una actitud impersonal con respecto a la circunstancia ("es conveniente que..."; "es necesario que...") o una postura subjetiva en la que el productor se implica personalmente ("creo que..."; "soy partidario de que..."). Las argumentos en torno a la probabilidad de una situación se expresan mediante recursos modales (verbos, adjetivos, adverbios etc.) y los argumentos evaluativos se reconocen mediante recursos calificativos o cuantitativos (adjetivos, adverbios, substantivos etc.).

Aunque a veces resulta difícil distinguir entre las relaciones argumentativas y las relaciones explicativas en un texto, el análisis de la intención y el tipo de texto con sus factores extratextuales suelen representar la pauta que condiciona la inferencia. En los casos en que la persuasión actúa como intención dominante (p.ej. los folletos turísticos), nos encontramos normalmente con relaciones argumentativas que aportan credibilidad a lo expresado. En los casos de textos que se inclinan sobre todo por señalar información, predominan las relaciones explicativas.

El cuarto grupo de relaciones funcionales de contenido lo forman las relaciones adversativas y concesivas, y guardan una estrecha relación con las relaciones de razonamiento y con las relaciones aclarativas anteriormente descritas. Sirven para enriquecer las expectativas del receptor sobre el contenido textual y establecer posibles conclusiones. Las adversativas suelen desempeñar el papel de la contraargumentación o corrección de la proposición anterior ("pero"; "sino que"; "no obstante" etc.), mientras que las concesivas apoyan las posibles conclusiones y suelen oponer una dificultad al cumplimiento de la proposición principal pero no lo impiden ("aunque"; "a pesar de que"; "si bien" etc.).

Los cuatro tipos básicos de relaciones de contenido remiten, en definitiva, a la informatividad o contenido informativo de un texto (relaciones descriptivas), al entendimiento conceptual (relaciones aclarativas, relaciones explicativas, relaciones adversativas) y al acercamiento del contenido textual (relaciones argumentativas, relaciones concesivas).

\subsection{Las relaciones de apoyo por interacción}

No obstante, estas relaciones de contenido necesitan de las relaciones de apoyo por interacción para su coherente encauzamiento comunicativo, puesto que la visua- 
lización de la información presentada en un texto desempeña un papel esencial durante la fase de lectura. En este sentido, al lector le interesa disponer de una visión informativa previa del texto con objeto de ahorrar tiempo y esfuerzo: saber de qué trata el texto en líneas generales, dónde puede encontrar una determinada información y si dicha información es relevante para él (cf. Hulst, 1995:121). Para ello, el texto dispone de indicadores que suministran información sobre el contenido, la estructura y la finalidad comunicativa. Estos indicadores textuales, denominados por Nord (1991) metacomunicativos, desempeñan una función subordinada, puesto que sirven como localizadores orientativos de la globalidad o de un determinado fragmento del texto. Funcionan, por lo tanto, como señales del camino en el texto. Sin embargo, existe una diferencia importante entre Nord y Hulst en cuanto a la concepción de estos marcadores textuales. Hulst no considera como indicadores metacomunicativos los ejemplos, los resúmenes o los textos que acompañan a las fotos u otros elementos no verbales en el sentido autónomo de Nord (1993), sino como recursos normalmente dependientes de las relaciones aclarativas. Además, los elementos metacomunicativos en el sentido de Nord también pueden aparecer como recursos dentro de las relaciones funcionales de contenido (por ejemplo en frases como "mi argumento en contra es..."; "con ello quiero recalcar que...") puesto que reflejan una determinada intención del productor. Por este motivo, Hulst prefiere utilizar el término "relaciones de apoyo por interacción" (interactionele ondersteuningen) como concepto dependiente, las cuales se dividen en cinco tipos.

Las relaciones de orientación señalan el camino al lector en cuanto al contenido informativo, actuando como indicadores del tema (o subtemas) y en ocasiones como indicadores de la estructura o configuración textual. Estos indicadores temáticos suelen localizarse al comienzo del texto y pueden estar representados por un sustantivo, grupo de sustantivos, una pregunta o una oración subordinada precedida por un pronombre interrogativo. Este grupo lo representan los títulos, subtítulos y ciertos encabezamientos temáticos, $\mathrm{y}$, en el nivel de la macroestructura, los índices y los resúmenes, entre otras posibilidades.

Las relaciones que apoyan la importancia del texto también suelen encontrarse al comienzo del texto y su función consiste en provocar la susceptibilidad del receptor con respecto a la información posterior. Un ejemplo de ello lo representan las preguntas o encabezamientos retóricos de la publicidad ("si usted no le regala una Osterizer, ¿quién se la regalará?").

El tercer grupo lo representan las relaciones que indican el motivo de producción del texto. Suelen aparecer en el apartado "opinión del lector" de revistas científicas de carácter divulgativo o en las "cartas al director" de los artículos periodísticos, e indican normalmente la intención del productor en corregir posibles errores de interpretación de un tema aparecido en la revista anterior o en remitirse a aspectos acontecidos en textos previos. En definitiva son reflejo de una reacción determinada sobre una acción anterior (por ejemplo: "véase Muy Interesante 2000/1, pp. 22-28").

El último grupo corresponde a las relaciones que despiertan la atención del receptor. Este es el caso de los enlaces de las páginas web, algunas informaciones que trae el correo publicitario y que aluden a las ventajas que el lector puede obtener con el texto (descuentos económicos, precios) y en algunas relaciones de conte- 
nido donde predominan aspectos persuasivos o directivos (citas, refranes, proverbios). Tratan por lo tanto de despertar el estímulo del lector sobre el texto.

Es importante señalar que la inferencia de estas relaciones de apoyo por interacción durante el análisis textual no siempre es clara en cuanto a su distinción respecto de las relaciones de contenido (p.ej. algunas citas). En algunos casos, como ocurre con determinados encabezamientos de fuerte carácter persuasivo o directivo, la finalidad textual de estos recursos cumple tanto con una función de contenido como con una función que trata de despertar la atención del receptor (polifuncionalidad).

\section{Aplicación del modelo: Analizando la informatividad de un texto}

Con objeto de ilustrar más detenidamente estas relaciones funcionales, presentamos un texto de intención persuasiva con el fin de analizar sus actos locutivos desde este enfoque basado en Hulst (1995:192-194). Los actos locutivos se resaltan en cursiva con su posterior indicación del tipo de relación funcional. A continuación comentaremos en líneas generales cada uno de estos tipos de relaciones:

(0) La capital de la alegría y del contento

[indicador del tema; relación de orientación (apoyo por interacción)]

(1a) Madrid es una ciudad abierta,

[relación descriptiva-característica: indica el carácter abierto de Madrid]

(1b) formada por quienes han llegado a ella de acá o allá,

[relación de razonamiento 土explicativa/relación descriptiva objeto-parte: población]

(1c) sin importar de dónde,

[relación adversativa: la procedencia de la población no es relevante]

(1d) porque en Madrid nadie se siente extraño.

[argumento de (1c)]

(2a) Madrid es una ciudad múltiple,

[relación descriptiva-característica: señala la variedad de Madrid]

(2b) con muchas facetas,

[relación aclarativa-paráfrasis de (2a)]

(2c) por eso los castizos hablan de los "Madriles":

[relación descriptiva-causal de motivo-consecuencia de (2a)+(2b)]

(2d) el Madrid de los Austrias

[relación aclarativa de adición o aposición de "Madriles": la familia real de los Habsburgo]

(2e) y el de los Borbones;

[relación aclarativa de adición o aposición de "Madriles": la familia real de los Borbones]

(2f) el goyesco, el romántico y el pintoresco;

[relación aclarativa de adición o aposición de "Madriles": Goya, romántico, peculiar] (2g) el popular y el sofisticado;

[relación aclarativa de adición o aposición de "Madriles": popular, elegante]

(2h) el tradicional y el moderno.

[relación aclarativa de adición o aposición de "Madriles": tradicional, actual] 
(3a) Pero, sobre todo, es una ciudad amable y divertida; [relación descriptiva-característica: sociable, bulliciosa] (3b) "la llaman la capital de la alegría y del contento", [argumento 1: cita de Tierno Galván] (3c) y la ONU la nominó como ciudad mensajera de la Paz. [argumento 2: nombramiento por la ONU] (4a) Y alguien tuvo que inventarse una palabra nueva: [argumento 3: necesidad de crear un neologismo] (4b) "la movida", [relación aclarativa de adición o aposición del nuevo término] (4c) porque es único el bullicio nocturno de Madrid [argumento 1 de (4a)] (4d) y nadie había acertado a expresarlo. [argumento 2 de (4a)]

(5) Porque Madrid es mucho Madrid.

[relación descriptiva-característica de Madrid /argumento de (4d) /relación que concentra la atención final del receptor (apoyo por interacción)]

El acto locutivo (0) funciona como relación de orientación-indicación del tema, si bien la macroestructura textual aparece fragmentada en tres proposiciones que actúan a su vez como subtemas: Madrid es una ciudad abierta (1a), Madrid es una ciudad multiple (2a) y Madrid es una ciudad amable y divertida (3a). A estos tres subtemas se subordinan respectivamente una serie de actos locutivos que funcionan como refuerzo comunicativo mediante la argumentación y otras relaciones funcionales. A la proposición (1a), que habla sobre el carácter abierto de Madrid, le sigue una aclaración cuyo contenido expresa la procedencia de sus habitantes. Sin embargo, es difícil definir la relación funcional existente entre (1a) y (1b). Por un lado podríamos decir que se trata de una relación descriptiva-característica, dado que aporta información sobre una propiedad de la ciudad. Por otro lado nos encontramos con una relación de razonamiento-explicativa, puesto que afirma la circunstancia que se está expresando en (1a). En este caso se aprecia una relación polifuncional, por lo que hemos considerado importante vincular ambas relaciones funcionales (también podría considerarse como una relación de adición aclarativa respecto de (1a), tal y como señala Hulst, 1995:193). El siguiente paso analítico en torno a los actos locutivos subordinados comunicativamente a (1a) corresponde a la relación adversativa entre (1b) y (1c). En la proposición (1c) se menciona explícitamente el origen de la población que en (1b) se indica vagamente con el término "de acá o allá". La función de este acto locutivo (1c) consiste, según nuestro punto de vista, en corregir la información de la proposición anterior, reforzado por el acto locutivo (1d) como su argumento de corroboración. Esta serie de actos locutivos señalan una estructura gradual donde cada acto locutivo posterior se subordina comunicativamente al acto locutivo anterior, y donde (1a) es la proposición básica.

A la proposición (2a), que habla sobre Madrid como ciudad múltiple, le sigue una relación aclarativa de paráfrasis representada por $(2 b)$, cuya función consiste en aclarar el adjetivo "múltiple". La proposición (2c) es una relación descriptiva-causal de motivo-consecuencia vinculada a (2a) y (2b), aunque también se podría decir 
que (2a) y (2b) actúan como relaciones de razonamiento de (2c) en torno al concepto "Madriles". Para entender el significado de "Madriles", se espera que el autor del texto utilice a continuación determinadas relaciones funcionales aclarativas, si tenemos en cuenta la lógica informativa dentro del criterio de coherencia. Efectivamente, los actos locutivos (2d), (2e), (2f), (2g) y (2h) funcionan como relaciones aclarativas de adición o aposición del concepto "Madriles".

La proposición (3a) adquiere un peso comunicativo especial en el texto recalcado por el marcador textual "pero, sobre todo". Funciona como relación descriptiva de característica, resaltando la cordialidad y diversión de Madrid. Para reforzar su estatus comunicativo, los actos locutivos (3b) y (3c) desempeñan el papel de argumentos que corroboran la necesidad de resaltar estos aspectos únicos de Madrid mediante una cita de Tierno Galván (3b), el nombramiento de Madrid como "ciudad Mensajera de la Paz" por la ONU (3c) y la necesidad de crear un nuevo término para designar la peculiar diversión de la ciudad (4a). A este tercer argumento (4a) le corresponden una serie de actos locutivos subordinados: (4b) funciona como relación aclarativa de adición o aposición del neologismo, (4c) actúa como argumento 1 de (4a) y (4d) también actúa como argumento 2 de (4a).

La proposición (5) puede definirse funcionalmente desde varios puntos de vista distintos. Por un lado, remite a (4d) como relación de argumento. Resalta el carácter único de Madrid en el sentido de que no hay palabras para expresar la peculiaridad de esta ciudad. También remite al tercer subtema (3a), con inclusión de sus correspondientes actos locutivos subsidiarios, mediante dicha argumentación. Por otro lado funciona como relación descriptiva de característica que resalta esta diferencia de Madrid con respecto a las restantes ciudades. En nuestra opinión, la conjunción causal "porque" al comienzo de la frase como marcador textual independiente, remite asimismo a una relación de apoyo por interacción que trata de concentrar en este enunciado toda la atención del receptor sobre lo dicho previamente a modo de conclusión.

\section{Comparando la informatividad entre textos: Un caso de estudio}

Con la finalidad de constatar la eficacia del modelo de Hulst, describiremos a continuación la metamorfosis informativa que se ha producido en un texto meta escrito en español partiendo del texto anteriormente descrito, y realizado por una estudiante en mis clases de traducción, en función de los aspectos pragmáticos y comunicativos establecidos por el profesor mediante un encargo. El objetivo metodológico con este ejercicio ha sido enseñar al estudiantado el modelo de Hulst y aplicarlo como apoyo metacognitivo para establecer la coherencia intertextual entre textos escritos en español a nivel informativo (compárese con otro caso de estudio en García Álvarez, en prensa).

Encargo: el objetivo comunicativo principal consiste en instruir a un receptor español de manera general (universitarios y adultos interesados en la vida cultural y social de Madrid; no especialistas en el tema) acerca de los lugares culturales y sociales más importantes que pueden visitarse en la capital de España (es decir, 
aumentar los conocimientos del receptor sobre determinadas acciones). La tipología elegida corresponde al folleto turístico. Dicho texto constituye el primero de una serie de textos instructivos posteriores que proporcionarán información adicional sobre cada uno de los lugares mencionados en el texto de la estudiante, y que se entregarán en una carpeta a las agencias de viaje para los turistas. Uno de los aspectos que hay que señalar en el texto es la ubicación geográfica más o menos aproximada de algunos de estos lugares de visita en la ciudad. Del texto de partida se recogerá tan sólo la información que concierne a Madrid como ciudad múltiple [2]. Es conveniente introducir en el texto recursos textuales de tipo persuasivo que complementen la consecución de la instrucción como objetivo comunicativo principal, dado que se trata de un folleto turístico. No se requiere introducir elementos no verbales ni subtextos. El espacio textual permitido para la autorregulación de la coherencia corresponde a una página como máximo (A4); interlineado "sencillo"; letra Times New Roman; tamaño 11. El establecimiento de los márgenes (alineación) para el texto los decidirá la estudiante. El texto se publicará dos meses después de su producción.

Texto de la estudiante:

[0]Visita a Madrid

[1a]Madrid es una ciudad múltiple, [1b] llena de sorpresas y de lugares para todos los gustos. [1c]Tanto el lejano Madrid de antiguos imperios como el Madrid moderno se reflejan en sus calles, en monumentos, edificios o parques, [1d]y un sinfín de lugares merecen ser visitados [1e]si quiere descubrir Madrid.

[2a]El Madrid de los Austrias hace referencia a aquella parte de la ciudad en la que reinó Carlos I y V de Alemania, [2b]bajo cuyo dominio Madrid comenzó a ser una de las ciudades más importantes del imperio, [2c]aunque sería Felipe II quien la nombraría capital de España. [2d]Se encuentran en esta zona edificios principalmente renacentistas y barrocos, [2e]como la Puerta del Sol, en pleno centro, [2f]y la Plaza Mayor, [2g]donde se encuentra la Casa de la Panadería. [2h]También la Catedral de San Isidro.

[3a]Si quiere descubrir el Madrid de los Borbones, [3b]la calle por la que debe caminar para ver las maravillas de esta época es por excelencia la Calle Alcalá, [3c]en la que se encuentra la Casa de Postas, la Iglesia de San José y la famosísima Puerta de Alcalá, [3d]en la Plaza de la Independencia. [3e]Perpendicular a esta calle se sitúa el Paseo del Prado, [3f]donde podrá ver las fuentes más hermosas: [3g]las de Cibeles, Apolo y Neptuno [3h](estas dos últimas en el Paseo de la Castellana), [3i]sin olvidar los Jardines Botánicos y el Observatorio Astronómico. [3j]En esta calle habría posteriores construcciones, [3k]tales como el Congreso de los Diputados, el Teatro de la Zarzuela, el Banco de España y, como no, el Museo del Prado. [31]Tan sólo cruzando la Puerta del Sol se encuentra la Plaza de Oriente, [3m]otro de los lugares más céntricos de la ciudad; [3n]en ella está el Teatro Real.

[4a]Cerca de aquí descubriremos [4b]que en Madrid también hay cabida para el romanticismo: [4c]el Parque del Retiro, [4d]sin duda el más impresionante de la ciudad, [4e]con bellos jardines y un lago en el centro. [4f]Este romanticismo se mezcla con lo pintoresco de las gentes que lo visitan, [4g]haciendo de él un alarde de alegría y expresividad. [4h]Dentro de este parque se encuentra el Palacio de Cristal, [4i]con plantas exóticas en su interior. 
[5a]Este siglo: [5b]en el Paseo de la Castellana y alrededores se encuentran los Jardines del Descubrimiento y el Centro Cultural de la Villa, [5c]así como una serie de construcciones basadas en la arquitectura moderna, [5d]como el Palacio de Congresos y Exposiciones y el Edificio Sollube. [5e]El Centro de Arte Reina Sofía, la Torre Windsor y la Torre Europa.

[6a]Los domingos, Madrid no deja de ser una ciudad ajetreada. [6b]Lejos del estrés diario se respira el ambiente popular: [6c]el Rastro ofrece la posibilidad de pasar un día agradable entre objetos muy variados. [6d]Tiene lugar en Ribera de Curtidores.

[7a]Si le apetece tomar café cuando atardece, [7b]hay muchos cafés decorados al estilo de la "Belle Epoque", [7c]entre los cuales debe destacarse el famoso Café Gijón.

[8a]Por otro lado, para disfrutar de la noche madrileña [8b]hay una amplia gama de pubs, tabernas, cafés y bares, [8c]situados principalmente entre la Puerta del Sol y la Plaza Santa Ana (calle Huertas), [8d]en la Plaza de Santa Bárbara y en Moncloa, [8e]cuyo ambiente es sobre todo universitario. [8f]En verano se pueden encontrar también terrazas, [8g]situadas en el Paseo de la Castellana, [8h]entre Cuzco y Paseo del Prado. [8i]Muchos de estos lugares se encuentran muy cerca entre sí, [8j]porque al madrileño no le gusta permanecer en un solo sitio; [8k]por eso se les llama "nómadas de la noche".

Las relaciones funcionales entre los actos locutivos del primer párrafo, cuya informatividad se expresa en función de la perspectiva cultural y social requerida por el encargo, se describen del siguiente modo:

[1a] funciona como relación descriptiva de característica, puesto que indica el carácter múltiple de Madrid, relación funcional que comparte con [2a] del texto de partida. [1b] muestra dos tipos de relaciones: por un lado constituye una relación de adición aclarativa al proporcionar el entendimiento del concepto "múltiple" del acto locutivo anterior y, por otro, se define como relación descriptiva de característica objeto-contenido, ya que aporta información sobre la propiedad particular de la capital de "estar llena de sorpresas y de lugares para todos los gustos". [1c] representa la necesidad de dar más información sobre el acto locutivo anterior. De hecho, este acto locutivo proporciona información descriptiva sobre Madrid basada en aspectos relacionados con el tiempo, el espacio y las partes/lugares: "tanto el lejano Madrid de antiguos imperios como el Madrid moderno" (tiempo) "se reflejan en" (espacio) sus calles, en monumentos, edificios o parques" (objeto-partes; objeto-lugares). Por otro lado, [1d] funciona como relación argumentativa que aporta credibilidad a lo dicho anteriormente, evaluando de este modo la calidad del objeto, es decir, Madrid. Dicho argumento se basa en la valoración personal de la estudiante reflejada a través del recurso calificativo y cuantitativo del substantivo "un sinfin de lugares" y del verbo "merecen ser visitados". Finalmente, [1e] representa una relación de apoyo por interacción que trata de despertar la atencion del receptor o su estímulo sobre el texto. En nuestra opinión, la producción de esta intención directiva realizada por la estudiante resulta acertada, puesto que contribuye eficazmente a la finalidad pretendida de que el receptor continúe interesado en leer la información textual posterior.

Mientras el acto locutivo [2a] del segundo párrafo basa su expresión lingüística en una relación descriptiva de característica de objeto-parte (el Madrid de los Aus- 
trias como parte integrante de la ciudad) y, a su vez, de parte-tiempo (en la que reinó Carlos I y V de Alemania), el acto locutivo [2b] remite a una relación descriptiva causal de actividad-resultado sobre el acto locutivo anterior, es decir, el hecho de que Madrid se convirtiera en una de las capitales más importantes a causa de la influencia directa de Carlos I. El contenido informativo de [2c] corrige, sin embargo, este contenido proposicional anterior de [2b], desempeñando la función de relación adversativa: "aunque sería Felipe II quien la nombraría capital de España". A continuación, [2d] establece una relación descriptiva objeto-parte y objeto-espacio/lugar sobre el Madrid de los Austrias de [2a], representada por la expresión "se encuentran en esta zona (objeto-espacio/lugar) edificios principalmente renacentistas y barrocos (objeto-parte)". Esta relación funcional se aclara posteriormente mediante el acto locutivo [2e] que actúa como relación de ilustración dentro de las relaciones aclarativas. Constituye de este modo un ejemplo específico del acto locutivo objeto-parte representado por "edificios" [2d]. [2f] se vincula a [2d]+[2a] como lugar/parte (Plaza Mayor) que se puede visitar en la zona de los Austrias. Por último, [2g] representa una relación de espacio/lugar vinculada a la información anterior sobre la Plaza Mayor ("donde se encuentra la Casa de la Panadería").

$\mathrm{El}$ acto locutivo [2h] funciona asimismo como una relación descriptiva de característica parte-lugar. Sin embargo, no queda claro el vínculo funcional de dicho acto locutivo con los anteriores: ¿a qué se refiere? ¿constituye una parte del acto locutivo [2f] que menciona la Plaza Mayor? ¿cómo parte-lugar de [2d] en alusión a la zona del Madrid de los Austrias en general? En nuestra opinión, el modo en que se ha expresado [2h] produce cierta ambigüedad relativa a su vínculo espacial con los actos locutivos anteriores. Nuestros conocimientos presupositivos acerca de la ubicación de estos lugares en la capital de España constituyen el camino correcto para descifrar dicha ambigüedad. Sabemos que en la Plaza Mayor no se encuentra precisamente la Catedral de San Isidro, sino en la zona general denominada como "Madrid de los Austrias". Para un receptor desconocedor de la ubicación aproximada de estos lugares, el acto locutivo [2h] necesita de conectores explícitos que vinculen dicha información con [2d], por ejemplo, "en este Madrid de los Austrias también se encuentra la Catedral de San Isidro". En este sentido, la estudiante no ha encauzado el grado de explicitud necesario en la informatividad para lograr una clara intención instructiva y, en consecuencia, la correcta ubicación geográfica de la Catedral de San Isidro.

Respecto de las relaciones funcionales del tercer párrafo, cabe destacar en primer lugar el acto locutivo [3a] como relación de apoyo por interacción y vinculada indirectamente al título del tema [0], al igual que [1e]. [3b] representa una relación funcional descriptiva de característica objeto-parte del Madrid de los Borbones (objeto) expresado en [3a], dado que alude a una de sus calles principales (parte). En este mismo acto locutivo, la información "para ver las maravillas de la época" establece una relación descriptiva de característica parte-contenido (la calle Alcalá expone las maravillas del Madrid de los Borbones). [3c] actúa como relación descriptiva de característica parte-lugar/espacio de [3b]. Su información expresa los lugares que se pueden visitar en la calle Alcalá. [3d] proporciona información muy concreta sobre la Puerta de Alcalá en [3c]; se define por lo tanto como relación de 
característica parte-lugar/espacio ("en la Plaza de la Independencia”). La coma establecida en el acto locutivo [3c] después de la Puerta de Alcalá, junto con los conocimientos presupositivos del receptor sobre la ubicación de dicho monumento, aclara cualquier indicio de ambigüedad. Se entiende que la Puerta de Alcalá se encuentra en la Plaza de la Independencia, no así la Casa de Postas y la Iglesia de San José. Asimismo, [3e] se caracteriza por ser una relación descriptiva de característica parte-espacio de [3b] ("perpendicular a esta calle”) con otra parte del Madrid de los Borbones ("se sitúa el Paseo del Prado"). Precisamente en alusión a esta parte (el Paseo del Prado), encontramos otra relación descriptiva posterior de característica de contenido-partes señalada por [3f]: “donde podrá ver las fuentes más hermosas". Esta información desemboca en una relación aclarativa de ilustración, al proporcionar ejemplos específicos de dicha fuentes: "las de Cibeles, Apolo y Neptuno" [3g]. Más específico resulta el acto locutivo posterior [3h] basado en una relación de contenido/partes-lugar/espacio respecto a las fuentes de Apolo y Neptuno: "estas dos últimas" (contenido-partes) "en el Paseo de la Castellana" (lugar/espacio). Como se podrá comprobar, la sucesión de actos locutivos procede de manera jerárquica (de lo general a lo más específico), subordinándose unos actos locutivos con otros.

[3i] representa otra relación descriptiva de característica de contenido/parte del Paseo del Prado [3e], puesto que alude a los Jardines Botánicos y el Observatorio Astrónomico como partes integrantes de dicho Paseo. [3j], como relación descriptiva de lugar-partes, muestra en su expresión lingüística un indicio de ambigüedad en cuanto a su vínculo funcional con los actos locutivos anteriores. La expresión "en esta calle" (lugar) produce, de hecho, dicha ambigüedad, puesto que no sabemos si remite exactamente a construcciones (partes) situadas en el Paseo del Prado [3e] o en el Paseo de la Castellana [3h]. Nuestros conocimientos presupositivos sobre Madrid aclaran dicha ambigüedad si planteamos la siguiente cuestión: ¿dónde están situados realmente el Congreso de los Diputados, el Teatro de la Zarzuela y el Banco de España?

La alumna confundió el "Paseo del Prado" con la "calle del Prado" a la hora de seleccionar la información. Es en la calle del Prado donde se encuentran precisamente estas tres instituciones. Por otro lado, la información concerniente a los actos locutivos [3k], [31], [3m] y [3n] no está ubicada en el Madrid de los Borbones sino en el Madrid del siglo XIX, si bien dicha estudiante señala implícitamente en el acto locutivo [3j] que en dicha calle "habría posteriores construcciones", lo cual alude posiblemente a este siglo XIX. De hecho, el Congreso de los Diputados, el Teatro de la Zarzuela, el Banco de España y el Museo del Prado pertenecen al Madrid del siglo XIX. En nuestra opinión, y en función del receptor al que va dirigido el texto de la estudiante, desconocedor por otro lado de estos aspectos sobre Madrid, hubiese sido conveniente explicitar dicha información temporal relacionada con estos lugares del Madrid romántico.

Al margen de estas objeciones, la estudiante encauza de manera óptima las siguientes relaciones funcionales en el tercer párrafo: [3k] se define como relación aclarativa de ilustración de [3j] con tres ejemplos relacionados con dichas construcciones (Congreso de los Diputados, Teatro de la Zarzuela, Banco de España); [31] 
constituye una relación descriptiva de característica espacio-parte relacionada con el Madrid de los Austrias ("tan sólo cruzando la Puerta del Sol") vinculada a su vez, y espacialmente, con otra parte del Madrid del siglo XIX ("se encuentra la Plaza de Oriente"). Por último, [3m] actúa como relación de característica-contenido que remite a una propiedad de la Plaza de Oriente en [31] y como relación de adición aclarativa que expresa la importancia geográfica de esta parte de Madrid: "otro de los lugares más céntricos de la ciudad". Y [3n] establece otra relación descriptiva de lugar-parte de [31]: "en ella" (lugar: Plaza de Oriente) "está el Teatro Real” (parte).

El cuarto párrafo comienza con una relación funcional de apoyo por interacción [4a] que indica el cambio hacia un nuevo subtema (Madrid romántico) y que emplea a su vez un recurso textual de alusión directa al receptor mediante el cual la estudiante se implica personalmente a modo de estrecha cercanía con la identidad del "otro", es decir, del receptor pretendido ("cerca de aquí descubriremos").

Al mismo tiempo, el acto locutivo [4a] constituye una relación funcional descriptiva de característica espacio-parte ("cerca de aqui"). Sin embargo, ¿a qué parte se refiere? Al igual que ha sucedido anteriormente con determinados actos locutivos, [4a] no expresa claramente su relación funcional espacial con actos locutivos anteriores. ¿Es la Plaza de Oriente [31] lo que está cerca del Parque del Retiro [4c]? ¿Acaso el Museo del Prado [3k]? Los textos documentales consultados por la estudiante para ampliar la informatividad de su texto demuestran que la ubicación del Parque del Retiro tiene lugar cerca del Museo del Prado. Sin embargo, la estudiante no ha optado por explicitar, mediante recursos cohesivos, el vínculo informativoinstructivo necesario entre [4a] y [3k].

[4b] expresa una relación descriptiva de objeto-contenido, donde se recoge la idea del Madrid romántico señalado por [2f] en el texto de partida. Asimismo consideramos que actúa simultáneamente como relación de apoyo por interacción (apoya la importancia del texto), dado que su función consiste precisamente en recalcar de un modo retórico los múltiples aspectos de Madrid, en este caso, el Romántico: "que en Madrid también hay cabida para el romanticismo". [4c] constituye una relación descriptiva de característica objeto/contenido-parte en relación con el acto locutivo anterior [4b], ya que señala el Parque del Retiro como parte integrante del Madrid (objeto) Romántico (contenido). Vinculados a este acto locutivo, [4d] manifiesta una relación descriptiva de característica contenido-parte, indicando precisamente una propiedad de dicho Parque ("sin duda el más impresionante de la ciudad") y una relación argumentativa-evaluativa de la estudiante sobre dicha propiedad, mientras que [4e] expresa el mismo tipo de relación funcional aunque con características concernientes a otras partes: con bellos jardines (parte) y un lago (parte) en el centro (espacio).

[4f] establece una relación descriptiva de característica-contenido que relaciona una propiedad de Madrid ("este romanticismo se mezcla") con otra propiedad ("con lo pintoresco de las gentes que lo visitan"). En este sentido, la estudiante está preservando, aunque expresada de otra manera, la misma idea de propiedad establecida por [2f] en el texto de partida, si bien relacionada en esta ocasión con el Parque del Retiro. [4g] se define como relación argumentativa de [4f]; constituye de este modo un argumento evaluativo de la estudiante: "haciendo de él un alarde de ale- 
gría y expresividad". Finalmente, [4h] guarda un estrecho vínculo con [4c], puesto que establece una relación funcional de característica lugar/espacio-parte ("dentro de este parque se encuentra el Palacio de Cristal"), y [4i] expresa a su vez una relación con el Palacio de Cristal [4h] de parte-espacio ("con plantas exóticas en su interior"). Respecto a esta última información, y en función de nuestros conocimientos presupositivos sobre el Palacio de Cristal, sabemos que en dicho recinto no existen actualmente plantas exóticas en su interior. Esta información incorrecta es probablemente fruto de una interpretación errónea del texto documental consultado por la estudiante.

[5a] se define como relación de apoyo por interacción (relación de orientación). En este sentido funciona como indicador de una nueva característica de la ciudad (Madrid moderno). Constituye una especie de encabezamiento que señala el camino al lector en cuanto al contenido informativo y la configuración textual. Vinculado a este acto locutivo, [5b] implica una relación descriptiva indirecta de característica de contenido (Madrid moderno) -parte (Paseo de la Castellana) y a su vez una relación descriptiva de lugar/espacio-partes ("en el Paseo de la Castellana y alrededores se encuentran los Jardines del Descubrimiento y el Centro Cultural de la Villa"). [5c] refleja del mismo modo su vínculo con el acto locutivo anterior ("en el Paseo de la Castellana") como característica de lugar/espacio-parte ("así como una serie de construcciones basadas en la arquitectura moderna"). Por último, [5d] y [5e] son ejemplos de [5c]: representan, en definitiva, dos relaciones aclarativas por ilustración.

[6a] funciona como relación de razonamiento argumentativa, aportando cierta evaluación sobre Madrid (los domingos, Madrid no deja de ser una ciudad ajetrea$d a)$, $\mathrm{y}$, al mismo tiempo, proporciona una relación descriptiva de característica objeto (Madrid/ciudad)-contenido (ajetreada) y objeto-tiempo (los domingos, Madrid no deja de ser una ciudad ajetreada), cuya aclaración viene posteriormente con el acto locutivo [6b]. Este último acto figura, por lo tanto, como relación de adición aclarativa sobre el concepto impreciso anterior: este "ajetreo" no se refiere al estrés cotidiano que produce la sociedad capitalista de las ciudades cosmopolitas, sino al Madrid popular y social de sus gentes (perspectiva social). Paralelamente a esta aclaración, [6b] expresa una relación descriptiva de característica objeto-contenido que preserva en cierto modo la idea del acto locutivo [2g] del texto de partida: El Madrid (objeto) popular (contenido).

[6c] constituye otra descripción de contenido-parte (el Rastro como componente de dicho Madrid popular) y, a su vez, expresa otro argumento que indica de manera implícita la conveniencia de esta parte de Madrid como lugar que merece ser visitado por su vida comercial ("...ofrece la posibilidad de pasar un día agradable entre objetos muy variados"). [6d] queda funcionalmente vinculado a [6c] como partelugar/espacio ("tiene lugar en Ribera de Curtidores").

La otra idea de $[2 \mathrm{~g}]$ del texto de partida relacionada con el Madrid sofisticado aparece implícitamente en el acto locutivo [7b] del texto de la estudiante, expresando una relación de partes (cafés)-contenido (al estilo Belle Epoque). Parte de la imagen mental que evocaría un receptor al leer este fragmento del texto es precisamente la sofisticación de los cafés, no sólo por el estilo artístico, sino también por ser 
centro de reunión de la intelectualidad madrileña. El acto locutivo anterior [7a] actúa como relación de apoyo por interacción, al igual que los anteriores actos locutivos [1e] y [3a], vinculado obviamente a [7b]. Por último, [7c] ilustra uno de los cafés más representativos de Madrid (relación aclarativa-ilustración).

[8a] presenta una relación de razonamiento-argumentativa para enfatizar la conveniencia de visitar los diferentes lugares nocturnos señalados por [8b]: "para disfrutar de la noche madrileña". Simultáneamente, este acto locutivo [8a] establece una relación descriptiva de contenido que recoge la idea del bullicio nocturno de Madrid por [4c] del texto de partida o que expresa implícitamente la idea del Madrid divertido de [3a] del texto de partida. Recordemos que la estudiante ha querido preservar dicha información al considerar el grupo de receptores universitarios al que va destinado su texto.

A continuación, [8b] constituye una relación descriptiva de característica de contenido (Madrid divertido) -partes (amplia gama de pubs, tabernas, cafés y bares), y $[8 \mathrm{c}]+[8 \mathrm{~d}]$ muestran una relación descriptiva con el acto anterior de partes (pubs, tabernas, cafés y bares) -espacio/lugares: "situados principalmente entre la Puerta del Sol y la Plaza de Santa Ana (calle Huertas), en la Plaza de Santa Bárbara y en Moncloa". [8e] constituye una relación descriptiva de contenido de los lugares mencionados en $[8 \mathrm{c}]+[8 \mathrm{~d}]$, señalando la propiedad de su ambiente universitario.

[8f] señala una relación descriptiva de característica de contenido (Madrid divertido) -tiempo (en verano) y parte (terrazas); [8g] indica una relación con el anterior de tipo descriptivo de parte (terrazas) - espacio/lugar (situadas en el Paseo de la Castellana) y [8h] funciona como relación de adición aclarativa de [8g]: "entre Cuzco y Paseo del Prado". Obsérvese cómo la mayor parte de estos actos locutivos muestran una información instructiva principalmente relacionada con la descripción y ubicación geográfica de ciertos lugares madrileños, un aspecto que no se contempla en el texto de partida, puesto que en este último, las instrucciones del encargo requieren la producción de la coherencia textual basada en la consecución de una intención diferente (informativa).

[8i] constituye una relación descriptiva de característica partes-contenido/espacio. En concreto, expresa la propiedad de cercanía de dichos lugares ("muchos de estos lugares se encuentran muy cerca entre si"), unida al siguiente acto locutivo [8j], el cual funciona a su vez como relación de razonamiento que argumenta la conveniencia de la situación espacial anterior ("porque al madrileño no le gusta permanecer en un solo sitio"). Por último, [8k] muestra una relación descriptiva causal de motivo-consecuencia respecto del acto locutivo anterior ("por eso se les llama nómadas de la noche").

\section{Conclusiones}

La descripción metodológica de estas relaciones funcionales a lo largo del texto de la estudiante demuestra que la mayor parte de las ideas producidas por la estudiante cumplen, en cuanto a la informatividad, con las instrucciones del encargo, a excepción de ciertos actos locutivos ([2h], [3j], [4a] y [4i]), que no manifiestan una 
informatividad bien encauzada, principalmente aquella relacionada con la ubicación geográfica correcta de ciertos lugares de Madrid.

El modelo funcional de Hulst, aplicado en el presente artículo a un caso de estudio, es de gran utilidad no solo para el análisis comparativo de textos escritos en el mismo idioma, sino también, y muy especialmente, para la comparación y evaluación de textos metas con textos originales en función de la informatividad. Como andamiaje metacognitivo, no solo es aplicable a la crítica de traducciones sino también a la didáctica de la traducción, pues su metalenguaje teórico sirve de guía para evitar las especulaciones interpretativas. Las fundamentaciones, en este sentido, adquieren un mayor rigor científico, lo cual fomenta el diálogo y la búsqueda de consenso hermenéutico entre docente y alumnado, o entre crítico y traductor.

\section{Referencias bibliográficas}

Beaugrande, R. / Dressler, W., Introduction to Text Linguistics. London / New York: Longman 1981.

García Álvarez, A.M., «Confusiones, aclaraciones y propuesta metodológica para el análisis de los conceptos funcionalistas de función y skopos en la práctica de la traducción», Sendebar 17 (2006), pp.187-218.

García Álvarez, A.M., «Comparando la informatividad de las macroestructuras textuales: análisis funcional entre los actos locutivos o proposiciones», en: MLAC10 Proceedings (Mapping language across cultures: Textual analysis in cross-cultural and intercultural communication). Universidad de Salamanca, 5-7 de julio 2010, en prensa.

House, J., A Model for Translation Quality Assessment. Tübingen: Gunter Narr Verlag 1977.

Hulst, J., De doeltekst centraal. Naar een functioneel model voor vertaalkritiek. Amsterdam: Perspectieven op taalgebruik, Thesis Publishers: Amsterdam 1995.

Mann, W.C./Thompson, S.A., "Rhetorical structure theory: Toward a functional theory of text organization", Text 8, (1988), pp. 243-281.

Nord, C., Text Analysis in Translation.Theory, Methodology, and Didactic Application of a Model for Translation-Oriented Text Analysis. Amsterdam: Rodopi 1991. [Trad. inglesa de C. Nord y P. Sparrow].

Nord, C., Einführung in das funktionale Übersetzen. Am Beispiel von Titeln und Überschriften. Tübingen/Basel: Francke 1993.

Reiss, K., Möglichkeiten und Grenzen der Übersetzungskritik. Kategorien und Kriterien für eine sachgerechte Beurteilung von Übersetzungen. München: Max Hueber 1971. 